
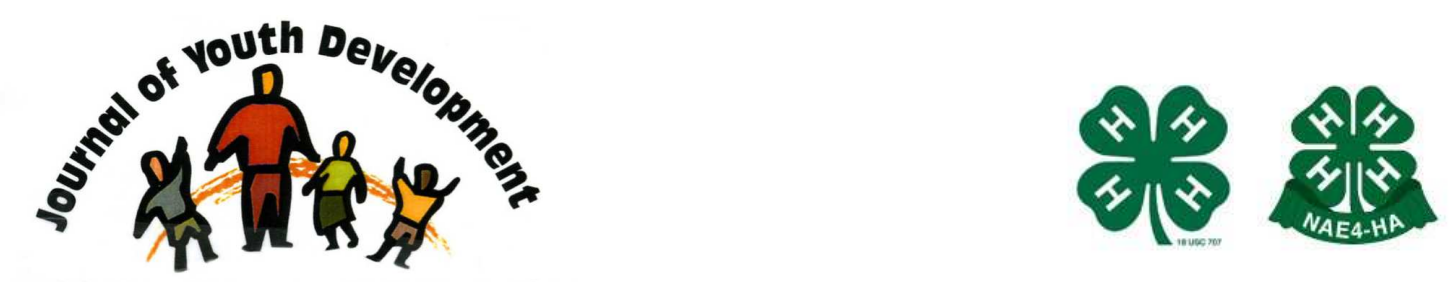

Bridging Research \& Practice

\title{
New Horizons: \\ Understanding the Processes and Practices of Youth Development
}

\author{
Reed W. Larson \\ University of Illinois \\ larsonr@illinois.edu
}

Hyeyoung Kang

State University of New York at Binghamton

S. Cole Perry

University of Illinois

Kathrin C. Walker

University of Minnesota 


\title{
JOURNAL OF YOUTH DEVELOPMENT \\ bridging research and practice

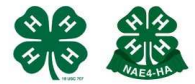

Volume 6, Number 3, Fall 2011

Article 110603FA010

\section{New Horizons: \\ Understanding the Processes and Practices of Youth Development}

\author{
Reed W. Larson and S. Cole Perry \\ University of Illinois \\ Hyeyoung Kang \\ State University of New York at Binghamton \\ Kathrin C. Walker \\ University of Minnesota
}

\begin{abstract}
This article presents new horizons for research on youth development by focusing on the challenges youth face in learning teamwork and in coming to terms with diversity. These are both essential competencies for navigating the "real world" of the $21^{\text {st }}$ century. We examine how youth experience these challenges within programs; also how they present second-order challenges to practitioners. The underlying message of this article is that it is essential for researchers to see programs from the point of view of the people in them. Researchers have learned quite a bit of what can be learned from arm's length: that programs can make a difference in youths' lives and that certain features of settings are associated with these changes. To go further, researchers need to work side-by-side with practitioners and youth to understand their complex worlds as they experience them.
\end{abstract}

\section{Introduction}

We know a lot about youth development, and we know very little. We know that youth programs can change young people's lives. Yet we know little about how these transformations actually occur. We know that programs are most effective when they create positive relationships for youth and engage them in challenging, authentic activities (Eccles \& Gootman, 2002; Mahoney, Vandell, Simpkins, \& Zarrett, 2009). Yet we know little about how to reliably create these conditions across programs, different groups of staff, and youth from diverse backgrounds. 
What we - at least those of us who are researchers - know little about is what happens inside programs. What are the developmental processes through which youth change? How do front line staff best support these processes? Expert youth practitioners have a rich fund of practical wisdom on these questions. Yet our field has not yet found a way to capture and codify this expertise in ways that can be evaluated or easily passed on to the next generation of practitioners.

To take on this agenda, it is essential to recognize that what happens in programs (as in life, more generally) is highly complex, in ways that often defy simplification. In the daily life of programs many things are happening at multiple levels at once. Everyone brings to the program their own goals, values, and prior experiences. People and events both inside and outside the program shape what happens.

At the extreme, this complexity can create contradictions, double-traps, and Catch-22s (Larson, 2011b). To take one example, we know that effective programs empower youth: they engage them as active participants. This is supported by dozens of studies (Durlak, Weissberg, \& Pachan, 2010). It seems simple enough. Yet research also shows that numerous well-meaning efforts to empower youth have led to train wrecks. Successfully empowering youth requires navigating a set of hidden pitfalls, unpacking assumptions, making numerous mid-course corrections, and articulating a logic model that takes these numerous complexities into account (Camino, 2005; Larson \& Angus, 2011).

We cannot expect research to provide easy answers. The slow and qualified success of decades of well-funded research in education is a cautionary tale. Humility is needed. To understand the processes and practices in programs, researchers should embrace complexity. An important priority should be systematic, descriptive research aimed at better understanding these complexities, especially as they are experienced by practitioners and youth. Description, of course, is a critical early stage in any field.

We argue, here, for an approach to understanding complexity that includes descriptive research on the challenges encountered by program staff. Within "challenges" we include problems, barriers, obstacles, tasks, and dilemmas - which are a frequent focus of applied research. Identifying and analyzing these challenges provides a valuable entry point for further research on effective practice, as well as for training practitioners (Ericsson, 2006; Larson \& Walker, 2010).

Before discussing practitioners' challenges, however, we are going to discuss the challenges and problems experienced by youth in programs. Understanding youth's challenges is important for similar reasons. Eminent scholars from Charles Darwin to Herbert Simon have stressed the importance of describing the complexities of the "problems" an organism encounters as a key to understanding its development. Indeed, the real-world skills that programs want youth to develop - responsibility, teamwork, agency, leadership, emotional maturity, etc. - are skills for dealing with difficult, often knotty problems.

Another reason to study the challenges faced by youth is that researchers - and society in general - so dramatically under-appreciate how difficult these challenges are. It is no wonder adolescents get so little respect. In the field of developmental psychology, for example, scholars marvel at the genius of toddlers, while seeing teens as cognitive underachievers (Kuhn, 2009). They fail to apprehend the profound complexity of the developmental tasks youth face. 
To prepare for adulthood, young people must address abstract, multi-layered puzzles for which there is no master guidebook. Many of these puzzles have been around for a long time: figuring out how to work in a team, learning to manage the peculiar dynamics of emotions. At the same time, the adult world that youth must enter is increasingly heterogeneous, fluid, and disorderly. Youth must find their way into opaque and changing labor markets and must navigate diverse cultural values and meaning systems (Larson, 2011b).

We are going describe this horizon for research on youth processes and staff practices by using two examples: the challenges youth face in learning teamwork and in coming to terms with cultural diversity. These are both essential competencies for navigating the "real world" of the $21^{\text {st }}$ century. We begin by examining how youth experiences these challenges within programs, then examine the second-order challenges that practitioners face in facilitating youths' developmental processes.

\section{The Developmental Challenges Faced by Youth}

\section{Teamwork}

Let's start with the puzzles youth face in learning to collaborate with others. This is a vital skill set for adulthood, one that has become increasingly important in the modern world (Parker, Ninomiya, \& Cogan, 1999). Many adults aren't very good at it. The skill set entailed is so unwieldy that school curricula avoid it.

Many youth programs fill the void left by schools, and provide opportunities to learn teamwork skills. But to do it well, our field needs to understand the difficult array of problems that youth encounter in working with others. Some were described by Blanca, a 14-year old in a program in which participants were trying to put together a magazine for the first time:

We had a deadline and everything. We came up with a plan a couple weeks ago and we're like, "OK, this is when this is gonna be due, this is when the first draft is due, this is when the last paper is due, this is when the picture is due, and and this is when we're gonna have everything go to the printer people that are gonna make our magazine."

So far, so good! But the group hit a set of snags familiar to most of us who work in teams:

A lot of things came up; a lot or people weren't sure about what their story was gonna be. People slack off and they're not doing what they're supposed to be doing. Some people are doing great and they're doing everything they're supposed to be. [But some youth said] "Oh, I had homework that came up and that was a little bit more important to me." A lot of people were like, "I changed my story at the last minute so I couldn't get any quotes from anybody."

Teamwork breaks down into an almost classical set of interpersonal puzzles. The full set is likely to include how to deal, not only with slackers, but know-it-alls, whiners, control freaks - and one's own conceits - among other things. Each represents a set of tough problems involving complex and abstract dynamics between people.

These interpersonal puzzles, in turn, start to show the skills youth need to learn. Exploratory studies suggest that under favorable conditions (which we discuss later) youth develop skills for 
effective communication, reciprocal exchanges, finding common ground, self-assertion, and constructing shared ruled that facilitate collaboration (Angus, 2008; Larson, 2007).

Charting these different challenges also begins to suggest the processes through which young people acquire teamwork skills. We found that teens in programs often learned teamwork through reasoned trial and error. They try strategies and then adapt them as problems arise. For example, after Blanca's group encountered the problems with their magazine, she reported:

So yesterday we sat down and we're like, "OK, let's look at this realistically. We see how much fun we can have with this. So let's get everyone back on track." So we fixed the calendar and we made it work. Now it's really reasonable, and we gave ourselves one or two days extra so that nobody can have an excuse and say the deadlines were too strict.

Blanca's group was learning teamwork skills. They learned to create nuanced strategies that addressed the obstacles encountered with their original plan. These strategies incorporated abstract, real-world concepts: motivation (having "fun") and the benefits of a margin of error in the deadline.

Methodical studies can tell us much more about these processes. Prior theory and research suggest that youth's experience of high investment, trust, and reciprocity with peers are important preconditions to these learning processes (Piaget, 1965; Selman, 2003). But this needs to be tested.

Skilled practitioners know a lot about these dynamics and complexities. They have developed logic models of how these developmental processes unfold and the variety of paths these can follow. Researchers can contribute by learning from them, as well as listening to youth and close observation of how these processes unfold over time. They can help by providing methodical description of the relationships between different challenges, the processes youth go through, and their learning outcomes.

\section{Coming to Terms with Diversity}

Another critical set of developmental challenges faced by youth is one they bring in from outside. Young people today can no longer reach adulthood by just following a single mold set by prior generations. They are confronted everyday with diverse values, codes of behavior, and meaning systems. Youths' lives at home, at school and in the media present them with crosstensions between different ways of thinking.

They face the task of coming to terms with this diversity. They must figure out the logic behind different codes, including unstated assumptions. This task is not just about the self (i.e. the well-studied problem of identity). It includes understanding others, learning how to relate to them, and developing skills to act across different worlds. To navigate adulthood (get a job, etc.), adolescents must learn to "code shift" and move between meaning systems (Larson, Wilson, Brown, Furstenberg, \& Verma, 2002). They must deal with cross pressures, split loyalties, multiple selves, and conflicting value systems.

Korean American immigrant youth, for example, may be expected to be respectful and compliant to parents' authority at home. Yet other contexts (peers, school, youth programs) may demand that they speak up, ask questions, and assert independent opinions. Such crosspressures are frequent across immigrant youth (Gaytan, Carhill, \& Suarez-Orozco, 2007). 
Cross tensions can be especially difficult for youth who are marginalized due to their social class, ability, sexuality, citizenship status, race or ethnicity (Russell \& Van Campen, 2011). Spencer (2006) elucidates how societal marginalization presents African American males with formidable, multi-layered developmental challenges.

These diversity challenges are relevant to all youth in contemporary pluralist societies. Several European American youth we interviewed at the Station (pseudonym) said the high value placed on tolerance in this program were "opposite" from their parents' values. This created a challenge. For many majority youth the challenge, paradoxically, is that they don't recognize this set of challenges (Perry, 2001). Many White youth (or their parents) deny cultural differences. They see Western values as the norm, thus contributing to the difficulties faced by non-majority youth. Our field too often does the same.

Researchers have important roles to play in helping us understand the many variations in the challenges youth face. Comprehending the breadth and depth of these challenges is crucial to helping our field support youth's dealing with them. What form do these cross-pressures take in programs with youth from different combinations of diverse groups? How are they manifest in language, peer relations, and youth's motivation in different activities? How do cross-pressures between home and programs play out?

Qualitative studies of effective programs suggest that youth's experience of naming and unpacking these issues is a crucial step in addressing this task (Halverson, 2009; Watkins, Larson, \& Sullivan, 2007). Having safe opportunities to examine one's own and others' beliefs appears to have powerful effects in helping young people discover the humanity in others and develop a more inclusive perspective (Hammack, 2006; Larson, Jensen, Kang, Griffith, Rompala, in press). We also believe that developing critical consciousness of the multiple layers of privilege and injustice is critical for all youth (Ginwright, 2010). These challenges and the developmental processes that address them need further study.

\section{Other Developmental Challenges}

These examples are just a sample of the many types of developmental challenges that youth can encounter or bring into programs. Often they involve reconciling cross-pressures, contradictions, or competing warrants. Kirshner, Pozzoboni, and Jones (2011) provide a lucid illustration of how youth conducting participatory action research were brought face-to-face with a conflict between their strong investment in a cause and the failure of their research findings to support the cause. With age, the challenges youth face increasingly involve hypotheticals - thinking though the range of possible impacts from a given action (Heath, 1999; Larson, 2011a). Researchers can contribute by embracing complexity. They can help us better understand the difficulties in the obstacles, dilemmas, and problems with which youth struggle.

\section{The Challenges Faced by Practitioners}

Programs can provide a safe space and fertile conditions for youth to work on these knotty developmental tasks. The challenges for programs and their staff include how to support the types of learning processes just discussed. Creating and sustaining these positive conditions (supportive relationships, constructive norms, meaningful activities) is by no means simple or formulaic. It involves planning and dealing with unexpected dilemmas of practice (Larson \& Walker, 2010). Beyond creating these conditions is the complex question: How do you help 
youth work on the difficult puzzles entailed in learning real-world skills? Let us again use our examples to discuss this question and how researchers can contribute.

\section{Teamwork}

How does program staff support youth's processes of learning to deal with the challenges of working in a team? With limited time and energy, staff can face difficult choices, for example, between working with a "slacker" to change her/his habits, helping the rest of the group work with those who don't contribute, or focusing on the completion of the team's project. If young people learn teamwork through trial and error, how much do you steer youth versus let them learn directly from outcomes (including big errors)?

Such is the complexity of youth work. No regression equation is going to answer these questions, but research can help practitioners better understand their choices, based on information collected across different programs and types of youth.

One set of challenges for staff is that peer dynamics can veer not just to "errors," but in truly problematic directions. Repeated studies show that, in worst case scenarios, unsupervised youth in programs teach each other not teamwork, but antisocial behavior (Dodge, Lansford, \& Dishion, 2006). We need to help staff better spot when this is happening and how to prevent it.

An equally hard set of practitioner challenges is when, where, and exactly how to support youth's learning constructive teamwork skills. Part of staff's role is helping to create an environment in which youth experience trust, reciprocity, and other pre-conditions for this learning. Beyond this are questions about how to effectively coach youth in their learning process? If youth's task includes developing new, more abstract and multi-level concepts for dealing with difficult puzzles, can we expect young people to discover these concepts on their own? Heath's (1999) research suggests that effective staff seed the environment with new language forms that provides youth conceptual tools for strategic thinking.

Researchers can help by studying how different practices help youth learn to address teamwork challenges. They have a role in describing the different peer scenarios, when they are likely to occur, and effective strategies used by staff.

\section{Coming to terms with diversity}

How can programs and staff help youth learn to navigate a world of diversity and cross-

tensions? How do you help young people learn to deal with experiences of prejudice - and examine their own assumptions and biases?

Programs can be part of the problem for youth. In our experience many adapt a post-racial, ethnically-blind ethos that rationalizes denial. In a mixed-race, faith-based program we studied, our questions about possible racial issues were dismissed with: "We are all children under God." McCready (2004) provides a vivid account of how the faculty advisor of a program for GLBTQ youth was insensitive to the unique forms of marginalization encountered by gay youth of color, leaving them confused and alienated.

A challenge is that both youth and adult staff often experience discomfort in talking about these highly charged issues. Bringing them out in the open can create intense self-consciousness. It is easy to feel judged from every direction. 
At the Station, mentioned earlier, staff addressed this challenge by making it a central focus of their program culture. Youth reported that a basic credo was: "All different, all equal." A young man explained, "One of the biggest parts of the Station is that they constantly encourage people to respect people regardless of what they seem to be or what their race, religion or creed or gender orientation." As a result, he went on to say, "In the Station, you don't feel selfconscious at all, like ever!"

They have made this challenge into a program mantra. Staff modeled the principle of "all different, all equal" in their relationships with youth, in fact they did not use the word "youth" because of its connotations of inequality. This approach was absorbed by program members. As one young person said, "You kind of adapt their values and their language and their accepting other people."

Of course the program mantra itself was only the beginning. The diverse membership of the Station provided youth many opportunities to learn about both differences and equality: about different ways of life and common humanity. The central focus the program gave to these issues encouraged youth to actively engage with them: to go deeper. Youth also learned to practice what they learned. Several youth said they learned to "stand for" each other.

Halverson (2009) describes several youth theater programs that employ a distinct method to do this. Youth first gathered stories that focused on a diversity issues (e.g., being an immigrant in America), then analyzed the common narrative and crafted plays that exposed this array of narratives. These plays acted out youth's experiences of typical acts of prejudice, struggle, humorous situations, and the dignity associated with diverse identities. This method appeared to be highly effective in helping youth address the cross-pressures they experienced.

Research can contribute by describing the different approaches taken by programs and help us understand how staff is effective in addressing youth's challenges. Cooper (2011) suggests that staff often play roles as "brokers" helping youth understand different cultural codes. But there is much to be learned about how to broker the wide variety of situations staff encounter. The complexity of the issues and the different permutations they take calls for "Description, description, description!"

Another ripe issue for researchers is to help us understand the interface youth experience between the program and families. As we mentioned, several members of the Station felt the program's values were "opposite" from their parents. The program provided a refuge that was important to the youth. There are important and difficult questions to be explored about when and how staff engages with youths' families.

\section{Conclusion: Embracing Complexity}

Deep complexity is part of the human condition. Young people have always faced the challenge of learning to navigate the multiple, sometimes entangled, levels of team relationships (Hammond, 2007). To make their way to adulthood in the $21^{\text {st }}$ century, they face increased challenges in understanding the enormous diversity of cultures, codes, and meaning systems that are a part of contemporary life; and they must learn to collaborate with people from diverse backgrounds. Programs can provide safe and fertile environments for youth to work on these - and many other - complex tasks associated with coming of age. 
Staff members face the second order challenges of how to support youth's learning to navigate these puzzles. How do you help youth learn to work with difficult collaborators - and with their own human conceits? How do you help broker their encounters with diversity and injustice? When do you teach; when do you let youth learn from trial and error? And how do you choose priorities among the many intense demands on your attention: the many things you should and could do?

This complexity requires that all in the field of youth development - including researchers approach their work with humility. We cannot expect to discover a simple variable or formula that, alone, provides a magic bullet that turns low quality programs into banner ones.

Researchers can contribute by helping describe, chart, and unpack the many forms of this complexity:

- What are the small and large challenges, obstacles, and problems experienced by youth and staff?

- How frequent are each encountered? When and under what condition do they occur?

- How does the array of challenges differ across types of program and youth populations?

- What strategies do youth and staff learn to deal with these varied challenges? What strategies are effective in what situations?

- How do expert practitioners differ in how they appraise challenges and the strategies they employ to address them (Cf. Walker \& Larson, submitted).

Challenges, of course, can be subjective. What one person sees as a problem, another may not. There is an important role for interpretation and critical discussion in unpacking human complexity and situating it in meaningful conceptual frameworks. At the same time, there is an important role for quantitative research in examining frequencies, testing multivariate relationships, and studying pathways.

Understanding challenges, problems, obstacles, and dilemmas is a good entry point for many ends. It can help define the agenda for researchers. More importantly, as we have seen, naming the challenges is important to youth's processes of learning. Blanca and her collaborators' recognition of the varied problems in their initial plan was the key to developing more reasonable strategies that took these complexities into account. Understanding and naming the challenges is also a key to staff's support for youth's development. At the Station, the motto, "All different, all equal," places the challenges of life in a world of diversity at the center of program members' consciousness, and inspires interactions and processes that take youth (and staff) deeper.

The underlying message of this article is that it is essential for researchers to see programs from the point of view of the people in them. Researchers have learned quite a bit of what can be learned from arm's length: that programs can make a difference in youths' lives, and that certain features of settings are associated with these changes. To go further, to contribute to practice, researchers need to work side by side with practitioners-and youth-to understand their complex worlds as they experience them. They need to provide evidence that informs the decision-making of youth workers and youth organizations (Bialechki \& Conn, 2011).

Bialechki and Conn (2011) describe a vision in which research is used to "infuse" youth organization with relevant evidence. This includes evidence that is "local" to the challenges faced by a particular program, program model, or population of youth. It also includes evidence 
about the challenges, youth processes, and effective staff practices found across varied settings - but with recognition that local programs may need to select and adapt these findings to the complexities of their setting.

Acknowledgement: We would like to thank the staff and youth who shared their experiences with us. We also thank the William T. Grant Foundation for its support of our research.

\section{References}

Angus, R. (2008). Learning Perspective Coordination in Youth Development Programs. Masters Thesis, University of Illinois.

Bialechki, M.D., \& Conn, M. (2011). Welcome to our world: Bridging youth development research in nonprofit and academic communities. Journal of Research on Adolescence, 21, 300306.

Camino, L. (2005). Pitfalls and promising practices of youth-adult partnerships: An evaluator's reflections. Journal of Community Psychology, 33, 75-85.

Cooper, C.R. (2011). Bridging multiple worlds: Cultures, identities and pathways to college. New York: Oxford.

Dodge, K., Lansford, J., \& Dishion, T. (2006). Deviant Peer Influences in Programs for Youth: Problems and Solutions (pp. 3-13). New York: Guilford.

Durlak, J.A., Weissberg, R.P., \& Pachan, M. (2010). A meta-analysis of after-school programs that seek to promote personal and social skills in children and adolescents. American Journal of Community Psychology, 45(3-4), 294-309.

Eccles, J.S., \& Gootman, J.A. (Eds.). (2002). Community programs to promote youth development. Committee on community-level programs for youth. Washington, D.C.: National Academy Press.

Ericsson, K.A. (2006). The influence of experience and deliberate practice on the development of superior expert performance. In. Ericsson, K.A., Charness, N., Feltovich, P.J., \& Hoffman, R.R. (Eds.). Cambridge handbook of expertise and expert performance: Its development, organization and content (pp. 683-704). Cambridge, UK: Cambridge.

Gaytan, F.X., Carhill, A., \& Suarez-Orozco, C. (2007). Understanding and responding to the needs of newcomer immigrant youth and families. The Prevention Researcher, 14, 10-13.

Ginwright, S. (2010). Black youth rising: Activism and radical healing in urban America. New York: Teachers College Press.

Halverson, E. (2009). Artistic production processes as venues for positive youth development. Revista Interuniversitaria de Formacion del Profesorado (Interuniversity Journal of Teacher Education), 23(3), 181-202. 
Hammack, P.L. (2006). Identity, conflict and coexistence: Life stories of Israeli and Palestinian adolescents. Journal of Adolescent Research, 21, 323-369.

Hammond, K.R. (2007). Beyond rationality: The search for wisdom in a troubled time. Oxford: Oxford University Press.

Heath, S.B. (1999). Dimensions of language development: Lessons from older children. In A.S. Masten (Ed.), Cultural processes in child development: The Minnesota symposium on child psychology, Vol. 29 (pp. 59-75). Mahwah, NY: Erlbaum.

Kuhn, D. (2009). Adolescent thinking. In R.M. Lerner \& L. Steinberg (Eds.), Handbook of Adolescent Psychology (3'd ed.) (Vol. 1, pp. 152-186). Hoboken, NJ: Wiley.

Kirshner, B., Pozzoboni, K., \& Jones, H. (2011). Learning how to manage bias: A case study of youth participatory action research. Applied Developmental Science, 27, 140-155.

Larson, R.W. (2011a). Adolescents' conscious processes of developing regulation: Learning to appraise challenges. In R.M. Lerner, J.V. Lerner, E.P. Bowers, S. Lewin-Bizan, S. Gestsdottir, \& J.B. Urban (Eds.). Thriving in childhood and adolescence: The role of self regulation processes: New Directions for Child and Adolescent Development, 133, 87-97.

Larson, R.W. (2011b). Positive development in a disorderly world. Journal of Research on Adolescence, 21, 317-334.

Larson, R.W. (2007). From "I" to "We": Development of the capacity for teamwork in youth programs. In R. Silbereisen \& R. Lerner (Eds.), Approaches to positive youth development (pp. 277-292). Thousand Oaks, CA: Sage.

Larson, R.W., \& Angus, R. (2011). Pursuing paradox: The role of adults in creating empowering settings for youth. In M. Aber, K. Maton, \& E. Seidman (Eds.), Empowering settings and voices for social change (pp. 65-93). New York: Oxford.

Larson, R.W., Hansen, D., \& Walker, K. (2005). Everybody's gotta give: Development of initiative and teamwork within a youth program. In J.L. Mahoney, R.W. Larson, \& J.S. Eccles (Eds.), Organized activities as contexts of development: Extracurricular activities, after-school and community programs. (pp. 159-183). Mahwah, NJ: Erlbaum.

Larson, R.W., Jensen, L.A., Kang, H., Griffith, A., \& Rompala, V. (in press). Peer Groups as a Crucible of Positive Value Development in a Global World. In G. Trommsdorff \& X. Chen (Eds.) Values, Religion, and Culture in Adolescent Development. New York: Cambridge University Press.

Larson, R.W., \& Walker, K. (2010). Dilemmas of practice: Challenges to program quality encountered by youth program leaders. American Journal of Community Psychology, 45, 338349.

Larson, R.W., Wilson, S., Brown, B.B., Furstenberg, F.F., \& Verma, S. (2002). Changes in adolescents' interpersonal experiences: Are they being prepared for adult relationships in the twenty-first century? Journal of Research on Adolescence, 12, 31-68. 
Mahoney, J.L., Vandell, D.L., Simpkins, S., \& Zarrett, N. (2009). Adolescent out-ofschool activities. In R.M. Lerner \& L. Steinberg (Eds.), Handbook of Adolescent Psychology (3 ${ }^{\text {rd }}$ ed.) (Vol. 2, pp. 228-267). Hoboken, NJ: Wiley. Mitchell, T. (Ed.). (2001). Global noise: Rap and hip-hop outside the USA. Middletown, CT: Wesleyan University Press.

McCready, L.T. (2004). Some challenges facing queer youth programs in urban high schools: Racial segregation and de-normalizing Whiteness. Journal of Gay \& Lesbian Issues in Education, 1, 37-51.

Parker, W., Ninomiya, A., \& Cogan, J. (1999). Educating world citizens: Toward multinational curriculum development. American Educational Research Journal, 36, 117145.

Perry, P. (2001). White means never having to say you're ethnic: White youth and the construction of "cultureless" identities. Journal of Contemporary Ethnography, 30, 56-89.

Piaget, J. (1965). The moral judgment of the child. Translated by T.A. Brown and C.E. Kaegi. Palo Alto, CA: Annual Reviews.

Russell, S. \& Van Campen, K. (2011). Diversity and inclusion in youth development: what we can learn from marginalized young people.

Selman, R.L. (2003). The promotion of social awareness: Powerful lessons from the partnership of developmental theory and classroom practice. New York: Russell Sage Foundation.

Spencer, M.B. (2006). Phenomenology and ecological systems theory: Development of diverse groups. In W. Damon (Eds.), Handbook of Child Psychology (6 ed.), Vol. 1 (pp. 829-892). Hoboken, NJ: Wiley.

Walker, \& Larson. (submitted). Youth worker reasoning about dilemmas encountered in practice: expert-novice differences.

Watkins, N.D., Larson, R.W., \& Sullivan, P.J. (2007). Bridging intergroup difference in a community youth program. American Behavioral Scientist, 51, p. 380-402.

(C) Copyright of Journal of Youth Development Bridging Research and Practice. Content may not be copied or emailed to multiple sites or posted to a listserv without copyright holder's express written permission. However, users may print, download or email articles for individual use. 